Rev. Ter. Ocup. Univ. São Paulo, v. 17, n. 3, p. 123-128, set./dez., 2006.

\title{
A transferência e a construção de um fazer criativo
}

\section{The transference and the building of a creative action}

\author{
Sylvia Ribeiro Fernandes ${ }^{1}$
}

FERNANDES, S. R. A transferência e a produção de um fazer criativo. Rev. Ter. Ocup. Univ. São Paulo, v. 17, n. 3, p. 123-128, set./dez., 2006.

\begin{abstract}
RESUMO: O artigo pretende apontar a relevância do conceito psicanalítico de transferência para a abordagem da relação terapeuta - paciente em um tratamento. Analisa a transferência tanto em seus aspectos de repetição, resistência e sugestão, como de suposição de saber. Por fim, articula a função da transferência na terapia ocupacional, que possibilita a construção permanente de uma ação comprometida com uma significação subjetiva.
\end{abstract}

DESCRITORES: Relações profissional-paciente. Transferência (Psicologia). Terapia ocupacional.

\begin{abstract}
$\Delta$ psicanálise considera que a relação entre o terapeuta e o paciente acontece em função do estabelecimento de um campo transferencial inerente à situação terapêutica. Desenvolve o conceito de transferência, um dos principais pilares da teoria psicanalítica. Mas, apesar de ser inicialmente definida pela psicanálise, a transferência pode ser um importante operador em outras práticas clínicas. O objetivo deste ensaio é mostrar como a transferência foi conceituada, apontar a importância de seu manejo para a eficácia do tratamento e refletir sobre sua função e especificidade em terapia ocupacional. Para tanto, analisa a estruturação do
\end{abstract}

conceito na teoria psicanalítica de Freud e Lacan, discute a pertinência de seu manejo em terapia ocupacional e aponta como ele pode ser desenvolvido no contexto singular de um tratamento em que o uso de atividades é fator diferencial.

A transferência surge na obra freudiana no relato do caso “Anna O" (1893/1980, p. 57), escrito em parceria com seu colega Breuer e, posteriormente, no posfácio do "caso Dora" (1905/1980, p. 107). Nestes dois escritos, ela ainda não é considerada uma condição determinante da terapêutica e se apresenta como um fenômeno periférico, constituindo um obstáculo ao sucesso do tratamento. É

\footnotetext{
${ }^{1}$ Terapeuta Ocupacional. Mestre e doutora em Comunicação e Semiótica pela PUC-SP.

Endereço para correspondência: Rua Sararé, 287 Apt. 44, Vila Madalena. CEP: 05452- 010. São Paulo, SP. e-mail: sylviafernandes@uol.com.br
} 
nos Escritos sobre a técnica (1912/1980, p. 133 e 1915/ 1980, p. 208) que a transferência é conceituada. Freud observa que, em determinado momento do tratamento, $\mathrm{o}$ paciente desenvolve um sentimento amoroso (de diferente intensidade dependendo do paciente) em relação ao terapeuta e que seu manejo pelo profissional pode determinar a continuidade do tratamento. Considera que este sentimento está a serviço de algumas causas inerentes à própria terapia e define então três formas, ou aspectos, da transferência: a sugestão, a repetição e a resistência.

A transferência como sugestão refere-se ao fato da própria situação terapêutica em si produzir um poder de sugestão. O paciente tem uma predisposição natural a ouvir e aceitar o que o terapeuta lhe diz. Assim, o profissional se utiliza dessa transferência pelo seu poder de influir sobre o outro. O próprio estilo do tratamento leva o paciente a se apegar ao terapeuta, pois eles se encontram freqüentemente, sistematicamente, e mantêm uma relação bastante singular. O paciente se abre e divide seus problemas mais íntimos com o terapeuta, sendo escutado e acompanhado por este. Assim, torna-se natural que o terapeuta tenha um certo poder de influência. Porém, ser colocado como objeto de amor do paciente extrapola o âmbito da sugestão. Por que um sentimento que poderia ficar no âmbito da afeição ou mesmo do reconhecimento se transforma, de repente, em algo da ordem da paixão?

Freud constata que a paixão transferencial é uma repetição. O que se repete é uma forma específica, um padrão, em que um sujeito se relaciona com um outro que está fortemente investido de afeto. Freud diz que cada indivíduo possui algo como uma placa estereotípica (clichê), ou várias placas, constantemente repetidas e que permite obter figuras por reimpressão (1912/1980, p. 133-4). Assim, o paciente "encaixa" o terapeuta em algum protótipo criado anteriormente, identificado à imago paterna, ou à materna, ou mesmo à fraterna. Por isso ele vai repetir com o terapeuta comportamentos originalmente atribuídos às relações infantis, eminentemente às relações com os pais. Ele atualiza, na figura do terapeuta, a forma de relacionar-se com as figuras parentais. A criança vive uma relação com os pais marcada por intenso investimento afetivo que é da ordem da paixão, com todos os correlatos dela, como amor, ódio, ciúme, rivalidade e etc. Assim, a relação com o terapeuta repete, atualizando este padrão. Por isso ela ser marcada pela paixão. É, portanto, um fenômeno ilusório, imaginário, porém vivido como real e atual.

A repetição é o aspecto mais conhecido da transferência e é identificado em muitas situações. Foi tão difundida e até mesmo banalizada, que os próprios pacientes a verbalizam. A questão é que nada adianta falar ao paciente que ele está repetindo e que não é a nós realmente que se dirige este sentimento (de amor ou ódio, por exemplo). Isso provoca somente mais ira no paciente. Mesmo porque não se trata da pessoa em si do terapeuta. Trata-se, como diz Miller (1992, p. 59), do significante do analista. Miller relata que há um artigo muito divertido de Thomas Szaz sobre a transferência que diz: "Quando me olham, a mim que sou feio como um piolho, me pergunto como é possível que se aferrem à minha pessoa" (SZAZ apud MILLER, 1992, p. 59). De fato, a imagem do terapeuta é inserida em um estereótipo e pouco importa a sua pessoa real.

O terceiro aspecto da transferência, como resistência, pode ser percebido no momento do tratamento em que parece haver um fechamento do inconsciente e o paciente passa a ocupar-se da relação com o terapeuta. Parece que tudo o que o levou à terapia desapareceu e que seu problema (ou sua solução) agora é o terapeuta. Surge, portanto, a transferência considerada por Freud no início de sua obra como um imprevisto indesejável, que vai perturbar o andamento do trabalho. Mas, se o terapeuta já estava lá, passível de ser utilizado como suporte da repetição, por que só agora é que a transferência surge?

A transferência surge justamente no momento em que o paciente está perto de deparar-se com certos conteúdos reprimidos, que são fonte de sofrimento. Assim, para se defender deste sofrimento, ele resiste à continuidade do tratamento e, para isso, "... nada melhor do que uma forte vivência atual na pessoa do terapeuta" (MEZAN, 1998, p. 253). Desta forma, o paciente repete para resistir. O tratamento se dá graças à transferência - pois seu surgimento demonstra que processos inconscientes foram ativados (por isso Freud aconselha não interpretar o inconsciente antes do surgimento da transferência no tratamento) - e apesar dela, pois é um tempo em que o inconsciente volta a se fechar (MILLER, 1992, p. 62).

Concluindo, a transferência na teoria freudiana é inerente ao tratamento, apresenta-se como repetição de padrões estereotipados de relação, que são constituídos a partir das primeiras relações infantis. Aparece no momento de resistência ao tratamento, justamente por este ter tocado em questões cruciais do sujeito. Estas se referem a conteúdos que, por sua natureza, provocam um duelo de forças. Se, por um lado, eles devem vir à tona para que o sintoma se desloque, por outro, há todo um esforço do sujeito em mantê-lo encapsulado. Há a dor de não saber e a dor de saber. Todo tratamento opera nesta luta entre o saber e o não saber.

Por muito tempo Lacan também centrou a importância da transferência, como a maioria dos psicanalistas 
freudianos, em seu aspecto de repetição. Porém, em seu Seminário 11 (1964/1998, p. 218), considerou que a sugestão, a repetição e a resistência são fenômenos transferenciais que giram em torno de um pivô, que constitui o fundamental na transferência. Define-o como o sujeito suposto saber. Ele significa, em termos gerais, que o paciente começa seu tratamento supondo que o terapeuta está de posse do saber sobre ele. Depois descobre (se o tratamento cumpre sua função) que não é bem assim, mas toda a terapia é sustentada por esta suposição. Assim, o terapeuta é um sujeito em que o paciente atribui um saber. Porém, não se trata de uma suposição de que o terapeuta seja detentor do saber. Segundo Nasio (1991, p.38), o terapeuta encarna mais do que possui o saber, trata-se dele representar o saber. Em muitas ocasiões o paciente atribui mesmo ao terapeuta uma certa função onisciente, mas ela não se sustenta. Logo, ele constata que seu terapeuta não sabe tudo ${ }^{(1)}$.

O saber atribuído ao terapeuta é um saber sobre o sentido, sobre a significação. O psicanalista, pelo próprio dispositivo analítico, sustenta que o sintoma tem um sentido, a fala tem um sentido, o tratamento tem um sentido. Nada é à toa, em vão. O que ele garante é que há uma verdade inconsciente. O seu saber é sobre o sujeito e, mais especificamente, sobre o sujeito do inconsciente. $\mathrm{O}$ paciente acredita que o psicanalista é quem sabe sobre o seu inconsciente e, portanto, sobre o significado do que se passa com ele. $O$ tratamento tem por objetivo fazer com que o paciente possa se apropriar deste saber sobre si, de maneira que o terapeuta não seja mais imprescindível para garantir a existência de sentido. Neste momento, a figura do terapeuta fica esvaziada de sua função transferencial e o sujeito pode, ele próprio, sustentar a função significante.

Pensar a transferência em termos de saber oferece um importante operador para a clínica. A terapia sustenta-se pela transferência, ou seja, pela suposição de que alguém sabe mais sobre nós que nós mesmos, e se desenvolve se o terapeuta pode sustentar este lugar ilusório, mas não se fixando nele. A ação ética do terapeuta é fazer com que o paciente possa se apropriar do saber que lhe concerne. Mas para isso, o terapeuta deve poder "aceitar" a transferência, ou seja, considerar que a transferência não é algo particular daquele atendimento, ou seja, daquele paciente e daquele terapeuta. É um fenômeno normal, inerente à terapia, sendo até mesmo esperado. $\mathrm{O}$ seu aparecimento é um sinal de que o tratamento está acontecendo, ou seja, está produzindo efeitos. Assim, apesar de possíveis constrangimentos causados e de uma sensação (por parte do terapeuta) de paralisação da terapia, o surgimento da transferência deve ser visto com "bons olhos".

A roupagem com que a transferência vem revestida o amor (no caso da transferência positiva) ou o ódio (no caso da negativa) pelo terapeuta - serve para um propósito muito claro, a resistência. Apesar de sabermos que ele foi produzido pela situação terapêutica, podendo ser considerado mais artificial que o amor cotidiano e, por isso, mais ilusório e imaginário que este, deve-se tratá-lo como efetivo (mesmo porque não se pode dizer que ele seja menos real que qualquer outra forma de amor). As recomendações de Freud a este aspecto são bastante pertinentes até os dias de hoje. Não se deve convencer o paciente de que este amor não é real, não se deve pedir que ele renuncie e sublime o sentimento, não se deve dar aulas ao paciente sobre o significado e propósito deste amor. Segundo Freud (1915/1980, p. 213), “... as paixões são pouco afetadas por discursos sublimes". Da mesma forma, não se deve dar margem a promessas para adiar uma complementação ou justificar impossibilidades.

A complementação na transferência não se refere somente a corresponder o sentimento do paciente pelo terapeuta, mas a aceitar ocupar o lugar que este procura colocá-lo. Às vezes pode ser o lugar de um pai severo, ou de uma mãe onipotente e supridora das necessidades, ou de alguém que ame incondicionalmente. $\mathrm{O}$ manejo da transferência implica em aceitá-la enquanto tal, mas não complementá-la, ou seja, não repetir com o paciente o que ele já viveu e que foi fonte de sofrimento.

Aceitar a transferência é não negar de antemão o que lhe é atribuído enquanto terapeuta. O paciente supõe que este tem o saber sobre ele. O terapeuta, por sua vez, sabe que o saber do sujeito deve ser construído por ele. Porém aceita esta suposição, mas sem ocupar realmente o lugar do saber, ou seja, sem se identificar com o detentor do saber. Naturalmente, o terapeuta tem um saber que é relativo à teoria e à técnica de sua clínica ou prática profissional, mas é um saber e não o saber sobre àquele sujeito específico. De nada adianta oferecer ao paciente seu saber, julgando assim que este terá acesso a revelações que produzirão efeitos terapêuticos. Mesmo porque, não se interpreta mais o inconsciente como na idade de ouro da psicanálise - não produz efeito, a própria interpretação banalizou-se.

\footnotetext{
${ }^{(1)}$ Em alguns casos específicos de psicose isso pode se mostrar de outra forma. O sujeito pode mesmo ter certeza que o terapeuta sabe, inclusive este pode ler seus pensamentos. Assim, o terapeuta não é um sujeito suposto saber, ele é o saber.
} 
O terapeuta pode ajudar muito mais se trabalhar no sentido de levar o paciente a se apropriar de seu próprio saber. Na clínica psicanalítica, o analisando, que inicialmente espera a palavra interpretativa do analista, passa ele mesmo a fazer suas significações, a associar um acontecimento a outro, a relembrar situações vividas e, assim, a construir um sentido novo e próprio à sua história. O psicanalista garante, com sua presença, a função interpretativa, ou seja, a permanência de sentido. Note-se que não é um sentido específico, como uma verdade que se deva encontrar. É muito mais uma promessa, uma aposta que há sentido, há significação. O paciente deve construir o seu. A função que sustenta essa posição de garantia, por parte do terapeuta, é a transferência.

A transferência foi inicialmente abordada e conceituada pela psicanálise, porém não se restringe ao tratamento psicanalítico estrito senso. Ela aparece na relação com o outro, eminentemente nas relações terapêuticas, mas também nas formações educacionais, religiosas, artísticas, entre outras. Ela aparece sempre em que alguém deposita certo saber em um outro e espera algo deste. Alguns fatores podem levar a pensar que a transferência na terapia ocupacional não acontece como na psicanálise. Pode-se supor que alguns elementos daquela, entre eles, o uso da atividade, o setting muitas vezes mais aberto que o clássico consultório e uma suposta dificuldade maior em manter a neutralidade, poderiam impossibilitar o estabelecimento e o manejo da transferência. Consideramos que estes fatores não são, de forma alguma, impeditivos da transferência e podem estar fundamentados em dois equívocos.

O primeiro é considerar que a transferência é algo singular do tipo de terapia, quando ela independe da terapia ou do terapeuta. É um fenômeno humano estabelecido pelo paciente diante da situação terapêutica, sendo que para ser suscitado pouco importa o nome ou o tipo de terapia a que o sujeito se submete. A diferença está muito mais na característica daquele paciente produzir determinado tipo de transferência. Enfim, é um fenômeno que depende do paciente e não da terapia ou do terapeuta. Assim, há transferência tanto pelo paciente da psicanálise, como pelo da terapia ocupacional.

O segundo equívoco parece ter sido criado em função de uma concepção específica de psicanálise e o manejo da transferência que lhe é próprio. A psicanálise, como todo corpo teórico minimamente desenvolvido, comporta certos pressupostos comuns, porém deriva-se em várias abordagens que priorizam certo aspecto ou outro, dependendo de escolhas éticas. Sendo assim, não há a psicanálise e sim várias abordagens psicanalíticas. A obra de Freud dá margem a, pelo menos, duas grandes posições frente ao inconsciente e à técnica psicanalítica - a construção de sentido e a busca arqueológica de um significado. São concepções ancoradas em uma certa posição ambígua de Freud em relação à sua própria teoria. Por um lado, aborda o fenômeno psíquico nos padrões da ciência positivista, buscando uma causa real. Assim, cria uma psicanálise mais comprometida com o factual, com o trauma, com a história "soterrada", com o encontro com o objeto. Porém em outros momentos da teoria, a psicanálise é construção de uma realidade singular, é criação de sentido. Não há objeto a ser resgatado e sim a construção de um novo objeto (FERNANDES, 2005, p. 105).

$\mathrm{Na}$ técnica psicanalítica mais comprometida com a primeira posição (a busca de significado) a transferência é muitas vezes interpretada no tratamento no sentido de promover condições regressivas para que o paciente possa reviver situações centradas nas relações infantis significativas e assim ter acesso ao vivido e recalcado. Desta forma, a transferência seria o que sustenta o encontro com algo, com determinados, ou mesmo determinado acontecimento real, sofrido no passado, que justificaria o sintoma do sujeito. Assim, por meio da experiência transferencial, o paciente teria acesso a elementos de sua história que foram "soterrados". A terapia é mais centrada na busca do que foi perdido, ou seja, no objeto da perda.

Já numa psicanálise em que o foco está mais na construção de sentido, mais no processo de busca do que no objeto propriamente da procura, a transferência é considerada uma função que possibilita a busca e não o encontro. O terapeuta é o acompanhante deste percurso. Está investido de uma função de saber, mas de um saber sobre o processo, mais sobre o andar do que sobre aonde chegar. Aqui, a transferência é considerada para qualquer intervenção terapêutica, porém no sentido de promover a continuidade do processo. Ela deve acontecer, pois é ela que investe a palavra do terapeuta de um sentido significante para aquele sujeito. Se não se atribui algum saber ao terapeuta, de nada adianta a sua palavra ou ato. Porém, a transferência não deve se tornar o foco das intervenções, sendo presentificada a todo o momento. Pois, o que se busca aqui é muito mais a construção de uma nova relação, de uma nova história, de novos objetos significativos.

Consideramos que a terapia ocupacional está muito mais próxima desta abordagem psicanalítica citada logo acima e, como ela, utiliza o fenômeno transferencial como uma ferramenta para favorecer um percurso de criação de objetos que sejam significativos para o sujeito. A 
transferência em terapia ocupacional, da mesma forma que na psicanálise, deve ser considerada em seus três aspectos: sugestão, repetição e resistência. Assim, as considerações sobre seu manejo aplicam-se da mesma forma, salvo adaptações quanto à técnica específica. Na psicanálise, por exemplo, uma das formas de não corresponder às demandas transferenciais é chamar o sujeito para associar livremente. Na terapia ocupacional, em que a regra básica é fazer atividade, o terapeuta deve promover ações que visem reconduzir o paciente à atividade. Esse fazer, considerado uma singularidade da terapia ocupacional, leva a transferência em terapia ocupacional a assumir uma particularidade. Como em seu caráter estrutural a transferência deve ser considerada enquanto suposição de saber sobre o outro, na terapia ocupacional atribui-se um saber específico ao terapeuta. É um saber sobre o fazer.

O elemento fundamental nesta prática profissional, que lhe dá especificidade, é a utilização de atividades. Assim, temos como elemento fundamental o fazer, apesar de não prescindir também da palavra. Se na psicanálise a palavra adquire o sentido de construções de signos em um discurso, na terapia ocupacional, as atividades criadas também fazem parte de uma sintaxe construída, modelada, costurada. Cabe ao terapeuta ocupacional sustentar a posição de que as atividades construídas têm um sentido, entrelaçam-se num discurso e são, assim, criações significantes. Este é o saber do terapeuta, ou seja, de que nada é feito em vão e que na terapia ocupacional a história é construída em ato, no próprio fazer cotidiano. As atividades não são objetos à parte do discurso verbal ou que tenham somente a função de promover o encontro com verdades inconscientes que se revelam. Elas, mais do que remeterem a uma história perdida, são a própria história construída.

Quando se pensa na construção de uma sintaxe, perde o sentido considerar os objetos concretos em terapia ocupacional de uma outra ordem, ou mesmo em oposição às construções psíquicas, sendo aqueles pertencentes à "realidade" e o psiquismo relativo ao mundo interno. As atividades são internas e externas ao mesmo tempo. O sujeito não se divide em um interior e um exterior, ele se constitui na ação, no fazer, no falar, no processo. Ele se constrói num artesanato constante, pois o inconsciente não é uma região obscura, ele é construído em ato, no fazer da vida.

$\mathrm{Na}$ transferência em terapia ocupacional o paciente supõe um saber do terapeuta não só sobre ele (sobre seu funcionamento psíquico e físico), mas sobre o fazer atividade, sobre o fazer do cotidiano. Da mesma forma que, na psicanálise, o psicanalista deve aceitar as suposições de saber do analisando sobre ele, o terapeuta ocupacional deve aceitar tais atribuições, mas ter como ideal o paciente poder se apropriar de um saber construído, um saber fazer com suas próprias mãos. Assim, se em muitos momentos o terapêutico é um fazer conjunto - terapeuta e paciente , em outros é o paciente fazer sozinho e ainda em outros é o paciente ensinando técnicas ao terapeuta. Trata-se de brincar de fazer e de saber. O sujeito, assim, aprende a construir seu saber. O saber sobre o fazer, sobre o seu cotidiano, sobre si.

O terapeuta ocupacional promove uma ação para que o sujeito possa se reconhecer e se apropriar de um "saber fazer", constituindo a sua marca em sua história. Esta marca não se encontra em algum recanto escondido, mas é construída pelo processo de fazer e pelos sentidos que a ação adquire a posteriori. É a transferência, em seu saber sobre o sujeito e sobre sua práxis, que sustenta a função terapêutica e faz com que o sujeito possa se constituir como autor de um fazer criativo.

FERNANDES, S. R. The transference and the building of a creative action. Rev. Ter. Ocup. Univ. São Paulo, v. 17, n. 3, p. 123-128, set./dez., 2006.

\begin{abstract}
This paper intends to point the relevance of the psychoanalytic concept of transference to the study of patient - therapist relation in a handling. It analyzes the transference in his aspects of repetition, resistance, suggestion and knowing supposition. Finally, it articulates the function of the transference in the occupational therapy that enables the permanent construction of an action committed with a subjective significance.
\end{abstract}

KEY WORDS: Professional-patient relations. Transference (Psychology). Occupational therapy. 
FERNANDES, S. R. A transferência e a produção de um fazer criativo. Rev. Ter. Ocup. Univ. São Paulo, v. 17, n. 3, p. 123-128, set./dez., 2006.

\section{REFERÊNCIAS}

FERNANDES, S. R. Uma teoria em construção: Freud e a criação artística. Manuscrítica: Rev. Crítica Genet., São Paulo, n. 13, p. 105-134, jan. 2005.

FREUD, S. Estudos sobre a histeria. In: Edição Standard Brasileira das Obras Psicológicas Completas de Sigmund Freud, v. 2. Rio de Janeiro: Imago, 1893/1980.

FREUD, S. Fragmento da análise de um caso de histeria. In: Edição Standard Brasileira das Obras Psicológicas Completas de Sigmund Freud, v. 7. Rio de Janeiro: Imago, 1905/1980.

FREUD, S. A dinâmica da transferência. In: Edição Standard Brasileira das Obras Psicológicas Completas de Sigmund Freud, v. 12. Rio de Janeiro: Imago, 1912/1980.

Recebido para publicação: Ago/2006

Aceito para publicação: Ago/2006
FREUD, S. Observações sobre o amor transferencial. In: Edição Standard Brasileira das Obras Psicológicas Completas de Sigmund Freud, v. 12. Rio de Janeiro: Imago, 1915/1980.

LACAN, J. O seminário, livro 11: os quatro conceitos fundamentais da psicanálise. Rio de Janeiro: Jorge Zahar, 1964/ 1998.

MEZAN, R. Tempo de muda. São Paulo: Companhia das Letras, 1998.

MILLER, J-A. Percurso de Lacan: uma introdução. Rio de Janeiro: Jorge Zahar Editor, 1992.

NASIO, J. D. Os olhos de Laura: o conceito de objeto a na teoria de Lacan. Porto Alegre: Artes Médicas, 1991. 